\title{
Is the Development of Family Functioning Dependent on Trajectories of Antisocial Behavior? A TRAILS Study
}

\author{
Sjoerd van Halem (i) ${ }^{1} \cdot$ Margot Peeters $^{2} \cdot$ Wilma A. M. Vollebergh ${ }^{2}$
}

Published online: 2 July 2020

(c) The Author(s) 2020

\begin{abstract}
Where previous studies have found consistent links between family factors and antisocial behavior, it is important to examine this relationship from a developmental perspective and account for heterogeneous antisocial development. In the present study, our goal was twofold: (1) identify and examine trajectories of self-reported antisocial behavior, and (2) compare the intercepts and slopes of family functioning of adolescents with different trajectories of antisocial behavior. We used a large national representative sample of 2230 Dutch boys and girls who we followed from approximately 10 to 22 years. We applied Latent class growth modeling to identify antisocial trajectories for boys and girls separately, across which the intercepts and slopes of family functioning were compared. We found four antisocial trajectories for boys and three antisocial trajectories for girls, which mostly corresponded with the trajectories found in previous literature. Further, we found that family functioning did not differ as a function of membership to a particular trajectory of antisocial behavior, neither on baseline measures nor on changes of family functioning across adolescence. Within this specific sample of adolescents, these results suggest that family functioning, as perceived by parents, remain stable regardless of antisocial behavior. Future research, in addition to using general family functioning measures, should also examine day-to-day family interactions, preferably also accounting for the perspective of the adolescent.
\end{abstract}

Keywords Trajectories $\cdot$ Family functioning $\cdot$ Antisocial behavior $\cdot$ Adolescence

\section{Highlights}

- The antisocial trajectories that we found in this study were in line with previous studies.

- Regardless of antisocial trajectory, family functioning remained stable across adolescence.

- Future research must study day-to-day family processes and follow these over longer periods.

Family plays an important role in the socialization process across childhood and adolescence. It is therefore not surprising, that criminological theories have emphasized the predictive role of family in explaining antisocial behavior. Hirshi's social control theory (2008) for instance states that the ties that we have with society prevent us from engaging in criminal behavior. Family represents one of our strongest

Sjoerd van Halem

s.vanhalem@uvt.nl

1 Developmental Psychology, Tilburg University, 5000 LE Tilburg, The Netherlands

2 Interdisciplinary Social Sciences, Utrecht University, Utrecht, The Netherlands social ties and, according to this theory, plays a crucial role in explaining the occurrence or absence of criminal behavior. In addition, learning theory emphasizes the role of family in explaining differences in antisocial behavior. Learning antisocial behavior in a family context can for instance happen through inconsistent and improper reinforcement or through modeling behavior (i.e., Bandura and Walters 1977). In line with theory, empirical studies are also in support of the idea that family processes are predictive of individual differences in antisocial behavior. A recent metaanalysis of Hoeve et al. (2009) for instance, summarized the results on the relationship between parenting and delinquency of 161 published and unpublished studies (1950-2008) and found consistent significant relationships between all included parenting dimensions and delinquency. 
Although evidence for the socialization process from family to child is strong, there are two important factors to take into account when studying this relationship. Of these factors, most studies either incorporate only one, or do not incorporate them at all. To begin with, despite the evidence for a socialization process from parent to child, this process is not considered static nor does the process has to be unidirectional. Just as a child develops, so does its family. In fact, both are likely to influence each other over time. Several developmental theories (e.g., Bowen 1978; Patterson 1982; Sameroff 2009) propose longitudinal bidirectional links between family and child. Scholars therefore need to account for the developmental nature of both the child as well as the family. There have been several studies concerned with studying the longitudinal associations between parenting and adolescent antisocial behavior (Buist et al. 2004; Gault-Sherman 2012; Jang and Smith 1997; Larsson et al. 2008; Liska and Reed 1985; Pardini et al. 2008; Reitz et al. 2006; Stewart et al. 2002; Thornberry et al. 1991). Most of these studies used cross-lagged models to confirm that overall negative family circumstances-such as poor parent-child communication, physical punishment, low positive reinforcement, and poor parental monitoringwere related to higher mean levels of adolescent antisocial behavior over time, and vice versa (Larsson et al. 2008; Pardini et al. 2008). However, Reitz et al. (2006) found only unidirectional effects in which adolescents' externalizing behavior had a negative influence on parental responsiveness, quality of the parent-adolescent relationship, and parental knowledge. Despite the findings of Reitz et al. (2006), most studies found support for a longitudinal bidirectional relationship between family variables and adolescent antisocial behavior, which underlines the importance of studying this relationship from a developmental perspective (Jang and Smith 1997; Larsson et al. 2008; Pardini et al. 2008).

Besides accounting for the longitudinal character of the relationship between family factors and antisocial behavior, studies have to account for the heterogeneity in the development of antisocial behavior across individuals. Following Moffit's developmental theory of crime, studies started to explore different antisocial trajectories of antisocial behavior. In a large cohort study, Odgers et al. (2008) identified four distinct trajectories of antisocial behavior: a high persistent group (i.e., life-course persistent), a group who starts showing antisocial behavior in early adolescence (i.e., adolescent-onset), a group that shows high levels of antisocial behavior in childhood but who desist in late childhood or early adolescence (i.e., childhood-limited), and a group with consistent low levels of antisocial behavior (i.e., abstainers). Not only do studies find different antisocial trajectories (see also: Fairchild et al. 2013; Moffitt et al. 1996; Moffitt 2006), each antisocial trajectory has been associated with a unique set of predictors (e.g., Odgers et al. 2008). For detailed overviews of the antisocial behavior trajectory literature, see: Piquero (2008) and Jennings and Reingle (2012). When examining the development of antisocial behavior and the relation with family factors, one should account for these different antisocial trajectories groups. Studies that accounted for different trajectories of antisocial behavior when relating family measures to antisocial behavior, have found that impaired family functioning in childhood is often related to antisocial trajectories in adolescence (e.g., Cavanagh and Cauffman 2017; Fergusson et al. 2000; Odgers et al. 2008; Roisman et al. 2010). In the study of Odgers et al. (2008), for instance, for both boys and girls, the life-course persistent path was predicted by several family risk variables such as; low socioeconomic status, maltreatment, poor mother's mental health, low IQ of the mother, and parental conviction. While faring better than life-course persistent boys and girls, childhood-limited adolescents had worse family characteristics in comparison to adolescents in the adolescent-onset and abstainer trajectories (Odgers et al. 2008). Cavanagh and Cauffman (2017) found that the relationship warmth between mothers and sons was predictive of offending trajectory membership. High initial relationship warmth, for instance, predicted membership in the low group over the high group.

To summarize, previous studies have found consistent links between family factors and antisocial behavior. It is important to both: (1) examine this relationship from a developmental perspective across time and (2) distinguish between different groups of individuals in terms of their antisocial development. We are not aware of studies that have accounted for both these points when examining the relationship between family factors and antisocial behavior. In our previous paragraphs, we did mention several studies that examined the relationship between family and antisocial behavior accounting for the development of both constructs over time. However, all of these studies treated antisocial development as a homogenous process and did not account for possible different antisocial trajectories. Likewise, we mentioned studies that did incorporate antisocial trajectories, but in turn, handled the family variables as a static construct (i.e., family factors in childhood). Based on the current literature it remains therefore unclear how family characteristics progress over time for different trajectories of antisocial behavior.

If we move beyond the family literature review and look for studies that are concerned with other risk factors of antisocial behavior, we still only found two studies that analyzed longitudinal associations between risk factors and antisocial behavior while accounting for different antisocial trajectories (Barker et al. 2010; Fergusson et al. 2000). Although these studies are not concerned with family as a risk factor, they provide at least some insight in to how risk 
factors generally develop for different antisocial trajectories. Fergusson et al. (2000) followed 900 children from New Zealand from birth to 18 years of age and found that affiliation with deviant peers closely followed the trajectories of antisocial behavior. For adolescent trajectories that remained relatively stable (e.g., life-course persistent, abstainers), levels of peer affiliation also remained stable. For the adolescent-onset group, deviant peer affiliation increased over time and thus mirrored the increase of antisocial behavior for individuals in this trajectory. No childhood-limited group was found in the study. Barker et al. (2010) studied the co-development of several risk factors of conduct problems in relation to the early onset persistent, childhood-limited, and adolescent-onset trajectories from the ages four to 13 years old. They found that risk factors were high and stable across all domains for early onset persistent individuals, childhood-limited youth showed decreases of risk factors from middle to late childhood accompanied by increases of prosocial behavior. Adolescent-onset individuals increased in adjustment problems while also decreasing in prosocial behavior over time. In short, although these studies were concerned with different risk factors and did not include family factors, they indicate that antisocial trajectories and the trajectories of risk and protective factors overall mirror one another over the entire course of childhood and (early) adolescence.

In sum, the studies of Barker et al. (2010) and Fergusson et al. (2000) indicate that antisocial trajectories and the trajectories of risk and protective factors generally mirror each other. Nonetheless, from previous literature it is unclear whether this applies for family risk factors as well. To improve our knowledge of the relationship between family functioning and antisocial behavior, the present study examines a large longitudinal national representative sample from the TRAILs study (TRacking Adolescents' Individual Lives Survey). The data from this ongoing Dutch study is particularly suited for our study aims. TRAILs includes 2230 participants, which means that there is enough power to account for heterogeneous development in antisocial behavior over time. Additionally, by following adolescent boys and girls from 10 to 22 years old, we can examine relationships between both constructs across an extended period spanning adolescence in its entirety. With this data, we therefore hope to improve our understanding of how family factors are related to various antisocial trajectories.

In this study, we specifically focus on the functioning of the entire family, opposed to studying isolated relationships within the family. Our aims are: (1) to identify and examine trajectories of self-reported antisocial behavior, and (2) to compare the intercepts and slopes of family functioning of adolescents with different trajectories of antisocial behavior. Based upon the negative bidirectional relationships found in previous literature (Jang and Smith 1997; Larsson et al. 2008; Pardini et al. 2008) and the studies of Barker et al. (2010) and Fergusson et al. (2000), we expect slopes and intercepts of family functioning to align with the shape of the different antisocial trajectories over the course of adolescence. Compared to antisocial trajectories that start out low, a trajectory with a relatively high starting point, should also have better initial values of family function. Additionally-compared to trajectories develop into a direction -relatively stable antisocial trajectories should be reflected by relatively stable slopes in family functioning. To conclude, although the main focus of this study is not to examine gender differences, antisocial behavior trajectories of boys and girls have been found to differ considerably in mean levels (e.g., Fontaine et al. 2009; Jennings et al. 2010; Moffitt 1993, Schaeffer et al. 2006). Since it is therefore unlikely that girls are classified together with boys of the same trajectory, it would be incorrect to model both genders concurrently. In the present paper, we will therefore examine boys and girls separately.

\section{Method}

\section{Participants}

Of the 2230 Dutch adolescents that participated in the study, 1098 (48.4 percent) were boys and 1132 (51.6 percent) were girls. Participants were on average 11.12 $(S D=0.56)$ years old in the first wave and 22.29 $(S D=0.65)$ years old in the fifth and final wave. Most participants had a Native Dutch ethnicity (86.5 percent). The rest of the sample included Moroccan, Turkish, Surinamese and adolescents of another ethnicity.

\section{Procedure}

Data of the current study is part of the TRacking Adolescents' Individual Lives Survey (TRAILS), a large longitudinal multi-informant study of several Dutch universities and research institutes that together aim to contribute to our understanding of adolescents' mental health and social development (Huisman et al. 2008). For five municipalities in the north of The Netherlands, information of all inhabitants born between 1 October 1989 and 30 September 1990 was required from the community registers. All 135 primary schools within this area were approached for participation, of which 122 schools agreed to participate (90.3 percent). Of the 3145 eligible children, 210 were excluded because of mental or physical illness, or because none of the parents spoke Dutch. Moroccan and Turkish parents that could not speak Dutch were interviewed in their native language. After thorough recruitment efforts, such as telephone calls, 
reminder letters, and home visits, a total of 2230 participants (76.0 percent) participated at the study's baseline (Oldehinkel et al. 2015). Questionnaires were administered every 2 years for five consecutive waves. All participants that were involved in the study provided written informed consent and the study's experimental protocol was accepted by the Central Committee on Research Involving Human subjects (CCMO).

\section{Measures}

\section{Antisocial behavior}

Antisocial behavior was assessed with the Antisocial Behaviour Questionnaire (ASBQ; Moffitt and Silva 1988). The questionnaire was administered over five waves (wave 1: 31 items, $\alpha=0.88$, wave 2: 26 items, $\alpha=0.86$, wave 3: 26 items, $\alpha=0.86$, wave $4: 26$ items; $\alpha=0.79$, wave $5: 26$ items; $\alpha=0.74$ ) and contained items about the past twelve months such as: "Have you stolen something from a store that was worth less than 10 euros?". Answer categories included: never, one time, two or three times, between four and six times, and seven times or more. In the first three waves there were age-specific items that applied on the school or family-context specifically, such as: "Have you damaged any school belongings", "Have you skipped class", or "Have you run away from home". I the fourth and fifth wave also items about the work-context were added, such as: "Have you deliberately given incorrect information to the tax authorities?" or "Stole something from your work that was more than 5 euros". However, to ensure that antisocial behavior was measured the same on each time point, only the 18 items that were the same across the waves were used for the analyses. The final construct was obtained using variety composite scores whereby the original items were first dichotomized. Variety scores are preferred over using frequency scores, as the latter is more likely to results in a measure with reduced internal consistency, lower stability and weaker associations with conceptually related variables compared to scales using variety scores (Bendixen et al. 2003). Also, frequency scores are more subject to recall bias (Monahan et al. 2009). Reliabilities of the ASBQ measure were all acceptable (wave $1, \alpha=0.82$, wave 2 , $\alpha=0.84$, wave $3, \alpha=0.85$, wave $4: \alpha=0.77$, wave 5 $\alpha=0.70$ ).

\section{Family functioning}

Family functioning was measured with the Family Assessment Device (FAD; Miller et al. 1985). This questionnaire was administered from one of the parents of the participant and contained 12 statements with four answer categories ranging from disagreeing with the statement to agreeing with the statement (i.e., strongly agree, agree, disagree, strongly disagree). For example: "We don't get along well in our family", "We can count on each other's support in difficult times", or "In our family we express feeling to each other". In $79 \%$ of the cases, the same parent responded to questionnaire across all five waves. Reliability was good for all five waves: wave 1: $\alpha=0.85$, wave $2: \alpha=0.87$, wave 3 : $\alpha=0.87$, wave $4: \alpha=0.87$, wave 5: 12 items, $\alpha=0.88$. The composite measure of Family functioning was acquired using mean scores. A high score on this variable represents negative family functioning.

\section{Data Analyses}

To identify different antisocial trajectories, latent class growth analyses (LCGA) were conducted. The best class solution was determined using four criteria (Muthén and Muthén 2000; Nagin 2005, Van de Schoot et al. 2017). First, adding an extra class in the model had to be accompanied by a decrease of the Bayesian Information Criterion (BIC), which is a measure indicative of relative model fit. Second, entropy values-indicative of classification accuracy—should be 0.75 or higher. Third, we chose the most parsimonious solution in cases where the additional class appears to be a slight variation of a class already found (Van De Schoot et al. 2017). Finally, to avoid that trajectories are based on outliers, or other random fluctuations in the data, but also to be able to conduct subsequent analyses (Bauer and Curran 2003; Muthén 2003) class sizes should be large enough. Of note, some studies used one percent as a strict cut-off (e.g., Meeus et al. 2012; Hill et al. 2000), which in our case means that a group would consist of roughly 11 individuals, which is likely too small for subsequent analyses.

Hereafter we defined a single growth model to examine whether the intercepts and slopes of family functioning across the five waves of data measurement were predicted by class membership of antisocial trajectories. Classes of trajectories of antisocial behavior that were calculated in the previous LCGAs were saved, converted into dummy variables, and included in the overall growth model as predictors of the intercept and slope of family functioning. See Fig. 1 for the model that was used. Absolute fit indices, including RMSEA, TLI, and CFI, were used to assess the model fit.

Multiple imputation was used to estimate the missing values on the items of the ASBQ and FAD, using the package mice in R (Van Buuren and Groothuis-Oudshoorn 2011). Predictive mean matching was used as imputation method, resulting in 15 imputed datasets. In the result section, we have reported on the pooled statistics. All subsequent analyses were conducted in Mplus version 7.2 (Muthén and Muthén 2000) using the Robust Maximum 


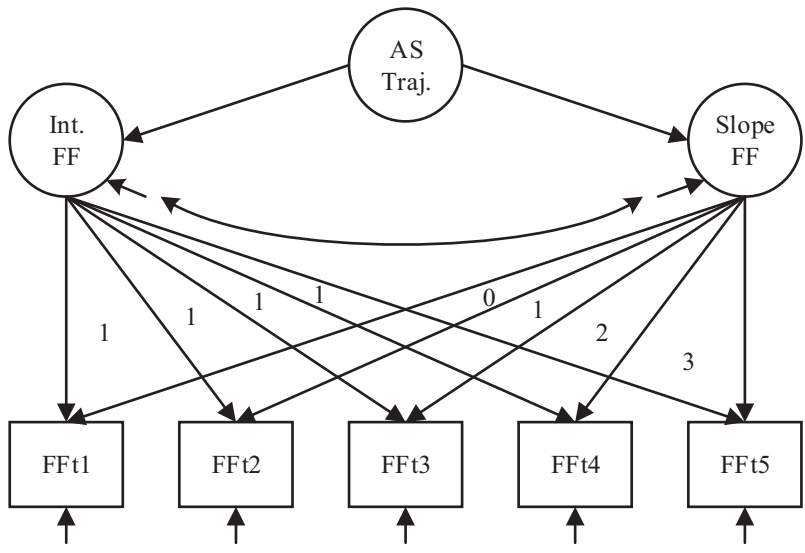

Fig. 1 Latent growth model for adolescent family functioning with intercepts and slopes predicted by antisocial trajectory. FF family functioning, Int Intercept, AS traj antisocial trajectory

Likelihood estimator which tends to perform better in the case of skewed data.

\section{Results}

\section{Descriptive Statistics}

Table 1 depicts the means and standard deviations of antisocial behavior and family functioning for boys and girls separately. For all five waves, boys were significantly more likely to report antisocial behavior than girls. Effect sizes ranged from small $(d=0.30)$ to medium $(d=0.48)$. No differences were found between boys and girls for parent reported family functioning across any of the waves of our study.

\section{Antisocial Behavior Trajectories}

Table 2 contains the fit statistics of the LCGAs for different class solutions for boys and girls separately, ranging from a one class solution to a six class solution. For boys, adding an additional class for all models was accompanied by a decrease in BIC. Entropy values of all the models were greater than 0.75 . When looking at the shape and size of the class solutions, as depicted in Fig. 2, both the three and four class models were considered. The five-class solution included a trajectory that was small and seemed to be a slight variation of the decreasing trajectory of the previous models. As the four class solution had a higher entropy value and we concluded that class sizes were large enough in the four cluster model for subsequent analyses, we selected this model as the best fitting model. Table 3 describes the intercepts and slopes of the four classes that were found in the data, which includes a high stable- (4 percent), moderate stable- $(9$ percent), high decreasing- (8 percent), and low decreasing (80 percent) antisocial trajectory.
Table 1 Means and standard deviations of antisocial behavior and family functioning for boys and girls

\begin{tabular}{|c|c|c|c|c|c|c|c|}
\hline \multirow[t]{2}{*}{ Variables } & \multicolumn{2}{|c|}{$\begin{array}{l}\text { Boys } \\
(N=1098)\end{array}$} & \multicolumn{2}{|c|}{$\begin{array}{l}\text { Girls } \\
(N=1132)\end{array}$} & \multirow[t]{2}{*}{$t$} & \multirow[t]{2}{*}{$p$} & \multirow[t]{2}{*}{ Cohen's $d$} \\
\hline & Mean & SD & Mean & $S D$ & & & \\
\hline \multicolumn{8}{|c|}{ Antisocial behavior } \\
\hline $\mathrm{T} 1$ & 2.90 & 3.04 & 1.32 & 1.86 & 14.74 & $<0.001$ & 0.48 \\
\hline $\mathrm{T} 2$ & 2.59 & 3.04 & 1.30 & 2.07 & 11.63 & $<0.001$ & 0.38 \\
\hline $\mathrm{T} 3$ & 2.36 & 3.12 & 1.19 & 2.08 & 10.41 & $<0.001$ & 0.34 \\
\hline $\mathrm{T} 4$ & 1.66 & 2.37 & 0.72 & 1.38 & 11.40 & $<0.001$ & 0.37 \\
\hline $\mathrm{T} 5$ & 1.21 & 2.01 & 0.57 & 1.15 & 9.28 & $<0.001$ & 0.30 \\
\hline \multicolumn{8}{|c|}{ Family (dys) functioning } \\
\hline $\mathrm{T} 1$ & 2.50 & 0.16 & 2.51 & 0.16 & -1.04 & 0.301 & -0.04 \\
\hline $\mathrm{T} 2$ & 2.48 & 0.20 & 2.48 & 0.18 & -0.61 & 0.545 & -0.02 \\
\hline $\mathrm{T} 3$ & 2.40 & 0.20 & 2.51 & 0.19 & -1.82 & 0.069 & -0.06 \\
\hline $\mathrm{T} 4$ & 2.53 & 0.17 & 2.52 & 0.18 & -1.35 & 0.177 & -0.05 \\
\hline $\mathrm{T} 5$ & 2.54 & 0.18 & 2.55 & 0.18 & -0.40 & 0.692 & -0.01 \\
\hline
\end{tabular}

A high score on the variable family functioning represents negative functioning

For girls, for each model in Table 2, adding an extra class resulted in a decrease in BIC. Entropy values were lower than 0.75 in the two class model but increased substantially in the three class model. Concerning the shapes and sample sizes of the antisocial trajectories, which are reported in Fig. 3, a three class solution was considered most appropriate. Adding an additional class, would create a class that was too small in size to examine. The intercepts and slopes of the three classes that were found are reported in Table 3 , which includes a moderate stable ( 2 percent), high decreasing- (5 percent), and low decreasing (93 percent) antisocial trajectory.

\section{Family Functioning across different Antisocial Trajectories}

To obtain the slope and intercept values of family functioning for each antisocial trajectory group separately, we first fitted a multi group latent class growth model with trajectory membership as grouping variable. The descriptive statistics of this model are reported in Table 4. Intercepts for all groups are on average more or less around the middle of the scale, were as slopes remained close to zero, demonstrating stability of family functioning across adolescence for each antisocial trajectory. The small standard errors for both intercepts and slopes, suggest that initial levels, as well as the development of family functioning as perceived by parents do not vary much within each antisocial trajectory.

To statistically compare the intercepts and slopes of family functioning across different antisocial behavior trajectories, a growth model of family functioning was defined 
Table 2 Models estimating antisocial trajectories for boys and girls using latent class growth analyses

\begin{tabular}{llllllll}
\hline \multirow{2}{*}{ Models } & \multicolumn{2}{l}{ Males $(N=1098)$} & & & \multicolumn{3}{l}{ Females $(N=1132)$} \\
\cline { 2 - 3 } & Loglikelihood & BIC & Entropy & & Loglikelihood & BIC & Entropy \\
\hline 1-Cluster & -13202.74 & 26454.50 & 1.00 & & -10909.15 & 21867.52 & 1.00 \\
2-Cluster & -12442.57 & 24955.15 & 0.97 & & -10324.91 & 20720.14 & 0.98 \\
3-Cluster & -12187.67 & 24466.35 & 0.91 & & $-\mathbf{1 0 0 8 5 . 5 6}$ & $\mathbf{2 0 2 6 2 . 5 3}$ & $\mathbf{0 . 9 7}$ \\
4-Cluster & $\mathbf{- 1 2 0 5 5 . 4 9}$ & $\mathbf{2 4 2 2 3 . 0 1}$ & $\mathbf{0 . 9 3}$ & & -9935.68 & 19983.87 & 0.97 \\
5-Cluster & -11959.45 & 24051.93 & 0.92 & & -9836.19 & 19805.98 & 0.97 \\
6-Cluster & -11846.57 & 23945.31 & 0.92 & & -9823.89 & 19728.54 & 0.97 \\
\hline
\end{tabular}

Rows in bold depict the class solution that is used for subsequent analyses
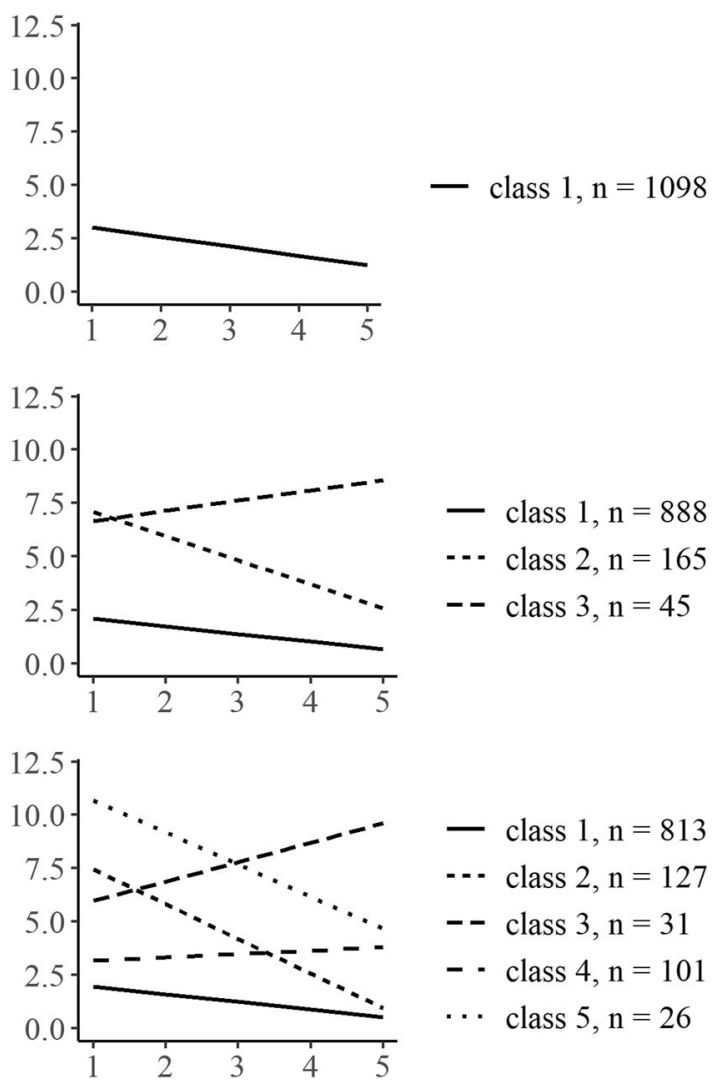

Fig. 2 Estimated means of the models estimating antisocial trajectories for boys using latent class growth analyses ranging from a one-class to six-class solution. The four-class solution was selected as the best

for boys and girls separately. The slopes and intercepts were regressed on class membership, using the low decreasing antisocial class as the reference category.

For boys a good fit was found $\left(\chi^{2}(19)=33.613, p=\right.$ $0.020, \quad$ RMSEA $^{1}=0.026, \quad 90 \%$ CI of RMSEA $=$ $0.010-0.041, \mathrm{CFI}=0.88, \mathrm{TLI}=0.84)$. The model did not explain a significant amount of variance of the intercept of family functioning $\left(R^{2}=0.05, S E=0.03, p=0.083\right)$, nor was this the case for the slope of family functioning $\left(R^{2}=\right.$ $0.05, S E=0.06, p=0.484$ ). For the intercepts of family

$\overline{1}$ RMSEA of the null model was 0.067
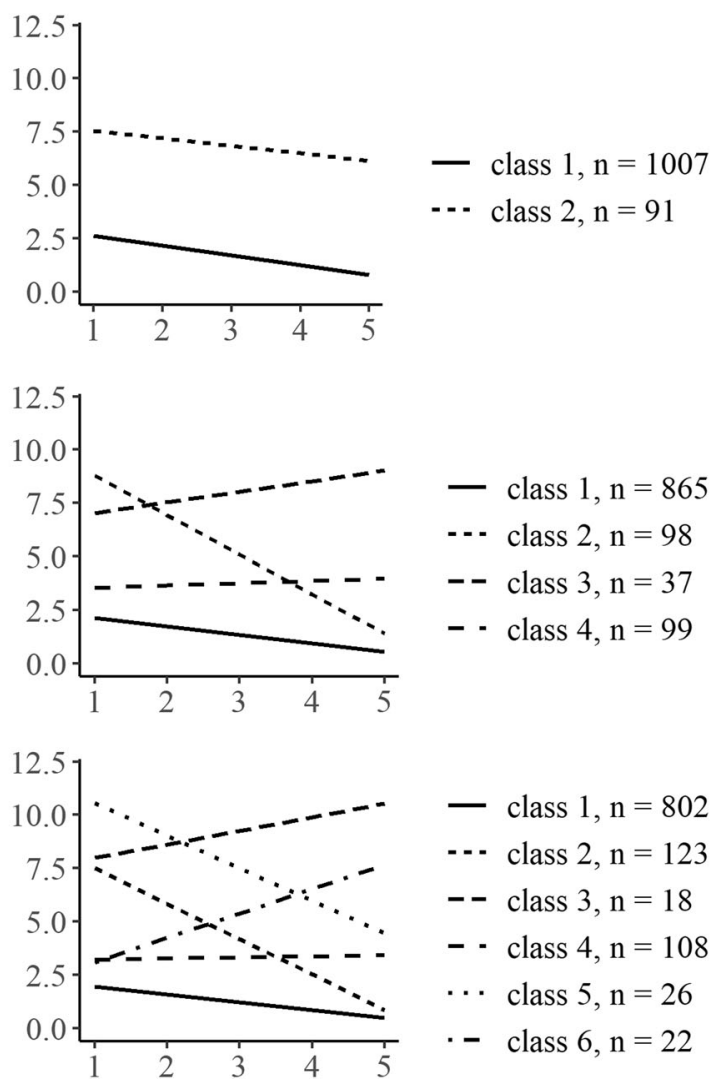

fitting model. See Table 2 for the fit statistics. The classes were labeled as follows: class $1=$ low decreasing, class $2=$ high decreasing, class $3=$ high stable, class $4=$ moderate stable

functioning there was a significant but small difference between the low decreasing and moderate stable antisocial trajectory groups $(B=0.05, \quad S E=0.07, \beta=0.18$, $p=0.004)$, but not for the other groups compared to the low decreasing antisocial trajectory group. See Table 5 for these statistics.

For girls reasonable fit was found $\left(\chi^{2}(16)=54.330\right.$, $p<0.001$, RMSEA ${ }^{2}=0.046,90 \%$ CI of RMSEA $=$ $0.033-0.060, \mathrm{CFI}=0.79$, TLI $=0.74)$. Again the model did not explain a significant amount of variance in either the

$\overline{{ }^{2} \text { RMSEA of the null model was } 0.097}$ 
Table 3 Antisocial behavior slopes and intercepts resulting from latent class growth analyses depicted per class

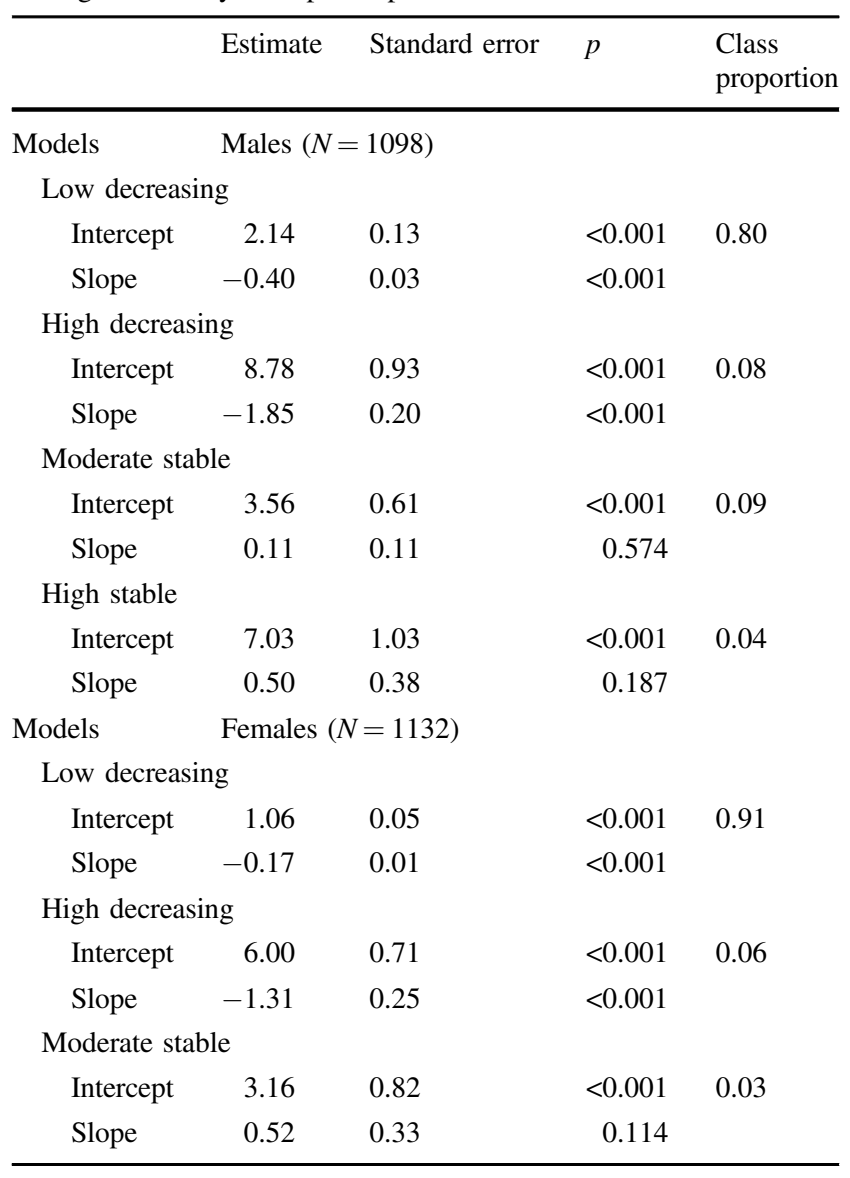

intercept $\left(R^{2}=0.00, S E=0.01, p=0.542\right)$ and the slope of family functioning $\left(R^{2}=0.01, S E=0.02, \quad p=0.603\right)$. Again, no differences were found between individuals with a low decreasing antisocial trajectory and any of the other trajectory groups on intercepts and slopes of family functioning. See Table 5 for these statistics.

In short, for both boys and girls we found that how parents perceive their family to be functioning was not related to the antisocial trajectory that their child is following. Also, irrespective of the antisocial trajectory, family functioning remained stable across adolescents for the eleven years of our study.

\section{Discussion}

Although previous studies have found consistent links between family factors and antisocial behavior, it is important to examine this relationship from a developmental perspective and account for heterogeneous antisocial development. In the present study, we accounted for both. We followed a large national representative sample of 2230 Dutch boys and girls from 10 to 22 years old. Our goal was twofold: (1) identify and examine trajectories of selfreported antisocial behavior, and (2) compare the intercepts and slopes of family functioning of adolescents with different trajectories of antisocial behavior. Latent class growth models (LCGA) were used to identify antisocial trajectories for boys and girls separately, across which we
Fig. 3 Estimated means of the models estimating antisocial trajectories for girls using latent class growth analyses ranging from a one-class to six-class solution. The three-class solution was selected as the best fitting model. See Table 2 for fit statistics. The classes were labeled as follows: class $1=$ low decreasing, class $2=$ high decreasing, class $3=$ moderate stable
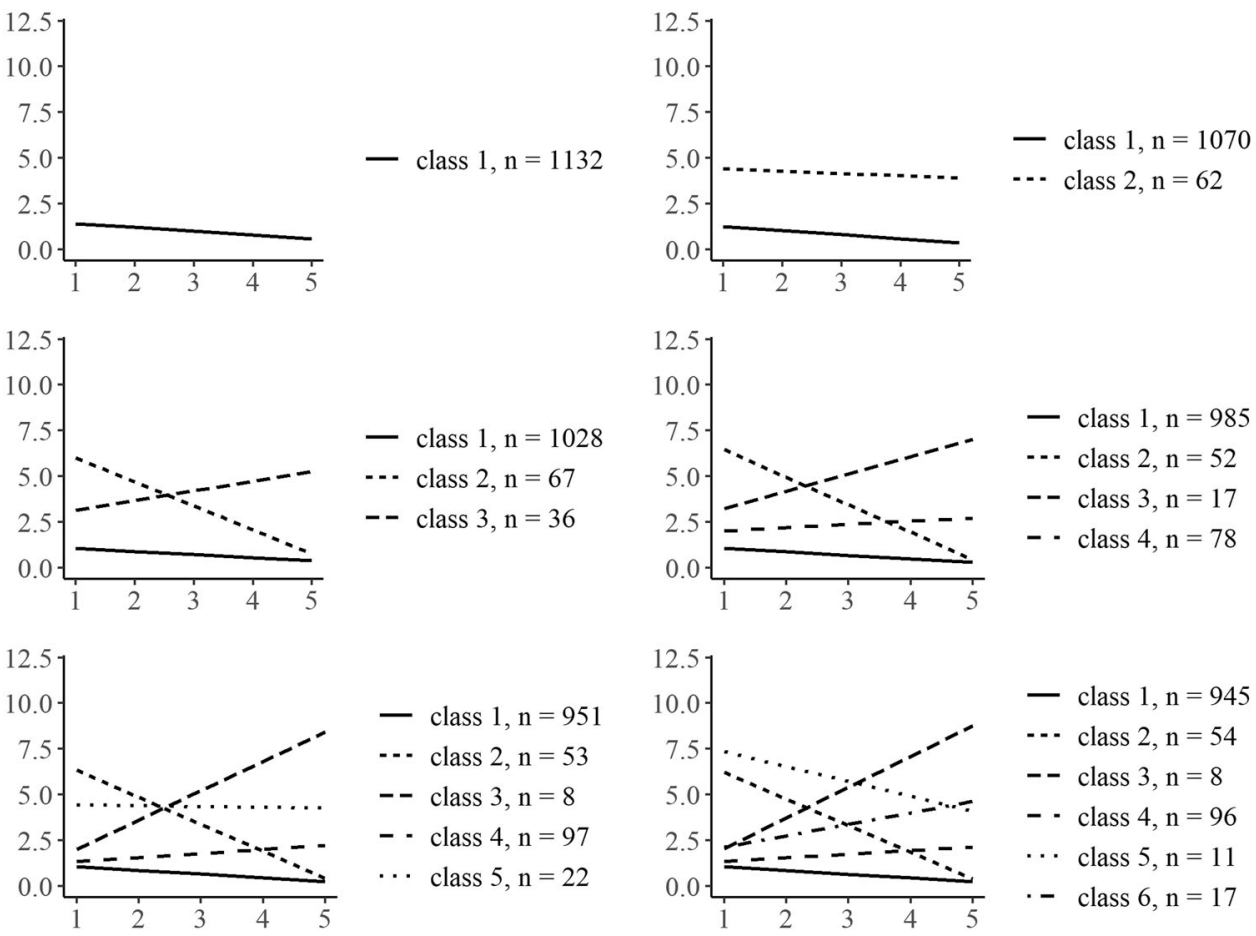
Table 4 Family functioning slopes and intercepts per antisocial trajectory membership resulting from a multi-group Latent Class Growth Analyses

\begin{tabular}{llrr}
\hline Antisocial trajectories & Family functioning & Mean & \multicolumn{1}{c}{ SE } \\
\hline Males $(N=1098)$ & & & \\
Low decreasing & Intercept & 2.47 & 0.01 \\
& Slope & 0.01 & $<0.01$ \\
Moderate stable & Intercept & 2.52 & 0.02 \\
& Slope & $<0.01$ & $<0.01$ \\
High decreasing & Intercept & 2.50 & 0.02 \\
& Slope & 0.01 & 0.01 \\
High stable & Intercept & 2.53 & 0.03 \\
& Slope & 0.01 & 0.01 \\
Females $(N=1132)$ & & & \\
Low decreasing & Intercept & 2.49 & 0.01 \\
& Slope & 0.01 & $<0.01$ \\
Moderate stable & Intercept & 2.52 & 0.07 \\
& Slope & 0.01 & 0.02 \\
High decreasing & Intercept & 2.48 & 0.03 \\
& Slope & 0.02 & 0.01 \\
\hline
\end{tabular}

Table 5 Antisocial trajectory membership regressed on family functioning slopes and intercepts

\begin{tabular}{lrrrr}
\hline Antisocial trajectory class & \multicolumn{1}{l}{$S$} & \multicolumn{1}{l}{$S E$} & $\beta$ & $p$ \\
\hline Males $(N=1098)$ & & & & \\
Intercept & & & & \\
Moderate stable & 0.05 & 0.07 & 0.18 & 0.004 \\
High decreasing & 0.03 & 0.07 & 0.10 & 0.145 \\
High stable & 0.05 & 0.07 & 0.12 & 0.090 \\
Slope & & & & \\
Moderate stable & -0.01 & 0.01 & -0.18 & 0.113 \\
High decreasing & -0.00 & 0.01 & -0.03 & 0.699 \\
High stable & -0.01 & 0.01 & -0.05 & 0.324 \\
Females $(N=1132)$ & & & & \\
Intercept & & & & \\
Moderate stable & 0.03 & 0.03 & 0.06 & 0.317 \\
High decreasing & -0.01 & 0.02 & -0.03 & 0.561 \\
Slope & & & & \\
Moderate stable & 0.01 & 0.01 & 0.07 & 0.520 \\
High decreasing & 0.00 & 0.02 & 0.05 & 0.614 \\
\hline
\end{tabular}

The low decreasing antisocial trajectory group has been assigned as reference category

compared the intercepts and slopes of family functioning. We found four antisocial trajectories for boys and three antisocial trajectories for girls, which largely corresponds with the trajectories found in previous literature (e.g., Odgers et al. 2008). For girls, although some previous literature identified a high and persistent trajectory, others did not find this trajectory for girls (Fontaine et al. 2009). Our study is in support of the latter as we found no stable high antisocial trajectory for girls. Our most important finding, however, was the absence of a relationship between family functioning slopes and intercepts on the one hand, and antisocial behavior trajectories on the other hand.

Regardless of the antisocial trajectory, family functioning remained stable for adolescents across the eleven years of our study. This seemingly goes against well-established and well-tested developmental theories (e.g., Bowen 1978; Patterson 1982; Sameroff 2009) that proposed longitudinal bidirectional links between family and child. Nonetheless, matters are likely to be more nuanced. In this study, we have looked at the general traits of a family as reported from the perspective of the parent. Our measure taps into different broad family facets, such as trust within a family, emotional openness, emotional disclosure, and acceptance towards other family members. In contrast, the developmental theories that we referred to mostly make predictions on a more day-to-day level, often from a within-person perspective. Patterson's Coercion theory, for instance, describes a within-family process in which child and parent negatively reinforce each other mutually, e.g. the child behaves difficult and receives a negative response, which elicits more problematic behavior-and the negative cycle continuous. These processes are likely more variant and occur at a different level, both in terms of constructs (parent-child interactions vs family norms) as in terms of time (day-to-day vs. years). Antisocial behavior of an adolescent might disrupt these day-to-day interactions between family members, but broader family norms that develop over a period covering adolescence in its entirety might not necessarily be influenced by it. Our results, in fact, suggest it to be stable irrespectively of antisocial behavior. Translating these results into practice, we speculate that it might be best for health care professionals to focus directly on the moment-to-moment manifestations of family dynamics, instead of focusing on broad family traits, which seem to be rather stable. Nonetheless, more research is needed to move beyond speculation and form concrete guidelines for health care professionals.

For future studies, we believe it is crucial to distinguish between different levels of the family environment when examining antisocial behavior over longer periods of time. We advise researchers to use measurement bursts of momentary assessments spanning across longer timeframes (Walls et al. 2011). In such designs, researchers can incorporate day-to-day family processes while studying broader family constructs over a longer period of time. As such, researchers can examine whether family dynamics are also constant and whether the development of these dynamics are related to the overall development of 
antisocial behavior. This allows researchers to study both within- and between family relationships. A recent systematic review shows that such studies are currently still relatively rare in the family literature (Boele et al. 2019).

\section{Limitations}

There are also potentially methodological explanations for the stability that we found for our family functioning construct. In this study, we have examined the family traits reported from the perspective of the parent. This perspective could substantially diverge from adolescents' perceptions of the family environment (e.g., McElhaney et al. 2008). It is for instance well established that parents are positively biased when it considers their own children (Phares et al. 1989). One could anticipate the same principle when asking parents about their families. Our results show that with only limited variance, on average, parents somewhat agree with the family functioning statements, pointing almost exactly at the middle of the scale. It would be valuable to compare this distribution with reports of their children when examining these items. A parent might for instance think that in his or her family it is easy to talk about feelings, or that family members support each other when needed. The adolescent, however, could experience this differently. These discrepancies are in itself interesting and can also be informative about the family environment. We therefore encourage future studies to use multi-informant measures when assessing the family environment.

Finally, the stability of our family function construct applies to a population sample that was relatively wellbehaved, at least in terms of antisocial behavior. Many participants did not score on our variety measure of antisocial behavior, indicating they did not engage in antisocial behavior whatsoever. Using a measure that was the same across all waves additionally came at the cost of excluding some age-specific items, which were often somewhat more moderate in terms of antisocial behavior. Overall our data was thus skewed-most adolescents rarely engaged in antisocial behavior or refrained from antisocial behavior entirely. Bearing this in mind, it could be the case that family values mostly remained stable because we did not have enough cases in which the antisocial behavior of the adolescent was truly disproportional or problematic. Nonetheless, our sample was relatively large and our trajectory analyses included several clusters of individuals that also followed more deviant trajectories. Nonetheless, it would be valuable to also examine more deviant adolescent samples, as an impact on family is more likely in such samples.

Notwithstanding these limitations, our study offers some important starting points for future studies. In our study's sample, which was particularly well behaved, family functioning as perceived by parents was not related to adolescents' antisocial behavior trajectories. Even in the case of antisocial trajectories, the family as a contextual factor remained constant and stable from the perspective of the parent. This is somewhat surprising in the light of previous studies that have consistently found relationships between family variables and antisocial behavior. To better understand the findings of the present study, we have argued that future research, in addition to using general family measures, should also examine day-to-day family processes and follow these processes using measurement burst designs.

\section{Compliance with Ethical Standards}

Conflict of Interest The authors declare that they have no conflict of interest.

Publisher's note Springer Nature remains neutral with regard to jurisdictional claims in published maps and institutional affiliations.

Open Access This article is licensed under a Creative Commons Attribution 4.0 International License, which permits use, sharing, adaptation, distribution and reproduction in any medium or format, as long as you give appropriate credit to the original author(s) and the source, provide a link to the Creative Commons license, and indicate if changes were made. The images or other third party material in this article are included in the article's Creative Commons license, unless indicated otherwise in a credit line to the material. If material is not included in the article's Creative Commons license and your intended use is not permitted by statutory regulation or exceeds the permitted use, you will need to obtain permission directly from the copyright holder. To view a copy of this license, visit http://creativecommons. org/licenses/by/4.0/.

\section{References}

Bandura, A., \& Walters, R. H. (1977). Social learning theory. Englewood Cliffs, NJ: Prentice-hall.

Barker, E. D., Oliver, B. R., \& Maughan, B. (2010). Co-occurring problems of early onset persistent, childhood limited, and adolescent onset conduct problem youth. Journal of Child Psychology and Psychiatry, 51, 1217-1226. https://doi.org/10.1111/j. 1469-7610.2010.02240.x.

Bauer, D. J., \& Curran, P. J. (2003). Distributional assumptions of growth mixture models: Implications for overextraction of latent trajectory classes. Psychological Methods, 8, 338-363. https:// doi.org/10.1037/1082-989X.8.3.338.

Bendixen, M., Endresen, I. M., \& Olweus, D. (2003). Variety and frequency scales of antisocial involvement: which one is better? Legal and Criminological Psychology, 8, 135-150. https://doi. org/10.1348/135532503322362924.

Boele, S., Denissen, J., Moopen, N., \& Keijsers, L. (2019). Over-time fluctuations in parenting and adolescent adaptation within families: A systematic review. Adolescent Research Review, 1-23. https://doi.org/10.1007/s40894-019-00127-9.

Bowen, M. (1978). Family treatment in clinical practice. New York, NY: Jason Aronson.

Buist, K. L., Deković, M., Meeus, W., \& van Aken, M. A. (2004). The reciprocal relationship between early adolescent attachment and internalizing and externalizing problem behaviour. Journal of 
adolescence, 27, 251-266. https://doi.org/10.1016/j.adolescence. 2003.11.012

Cavanagh, C., \& Cauffman, E. (2017). The longitudinal association of relationship quality and reoffending among first-time juvenile offenders and their mothers. Journal of youth and adolescence, 46, 1533-1546. https://doi.org/10.1007/s10964-017-0679-3.

Fairchild, G., Goozen, S. H., Calder, A. J., \& Goodyer, I. M. (2013). Research review: Evaluating and reformulating the developmental taxonomic theory of antisocial behaviour. Journal of Child Psychology and Psychiatry, 54, 924-940. https://doi.org/ $10.1111 /$ jcpp. 12102 .

Fergusson, D. M., Horwood, L., \& Nagin, D. S. (2000). Offending Trajectories in a New Zealand Birth Cohort. Criminology, 38, 525-552. https://doi.org/10.1111/j.1745-9125.2000.tb00898.x.

Fontaine, N., Carbonneau, R., Vitaro, F., Barker, E. D., \& Tremblay, R. E. (2009). Research review: a critical review of studies on the developmental trajectories of antisocial behavior in females. Journal of Child Psychology and Psychiatry, 50, 363-385. https://doi.org/10.1111/j.1469-7610.2008.01949.x.

Gault-Sherman, M. (2012). It's a two-way street: the bidirectional relationship between parenting and delinquency. Journal of youth and adolescence, 41, 121-145. https://doi.org/10.1007/s10964011-9656-4.

Hill, K. G., White, H. R., Chung, I.-J., Hawkins, J. D., \& Catalano, R. F. (2000). Early adult outcomes of adolescent binge drinking: Person and variable-centered analyses of binge drinking trajectories. Alcoholism, Clinical and Experimental Research, 24, 892-901. https://doi.org/10.1111/j.1530-0277.2000.tb02071.x.

Hoeve, M., Dubas, J. S., Eichelsheim, V. I., Van der Laan, P. H., Smeenk, W., \& Gerris, J. R. (2009). The relationship between parenting and delinquency: a meta-analysis. Journal of abnormal child psychology, 37(6), 749-775. https://doi.org/10.1007/ s10802-009-9310-8.

Huisman, M., Oldehinkel, A. J., de Winter, A., Minderaa, R. B., de Bildt, A., Huizink, A. C., \& Ormel, J. (2008). Cohort profile: the Dutch 'TRacking adolescents' individual lives' survey'; TRAILS. International Journal of Epidemiology, 37, 1227-1235. https://doi.org/10.1093/ije/dym273.

Jang, S. J., \& Smith, C. A. (1997). A test of reciprocal causal relationships among parental supervision, affective ties, and delinquency. Journal of Research in Crime and Delinquency, 34, 307-336. https://doi.org/10.1177/0022427897034003002.

Jennings, W. G., Maldonado-Molina, M. M., \& Komro, K. A. (2010). Sex similarities/differences in trajectories of delinquency among urban Chicago youth: the role of delinquent peers. American Journal of Criminal Justice, 35, 56-75. https://doi.org/10.1007/ s12103-009-9066-2.

Jennings, W. G., \& Reingle, J. M. (2012). On the number and shape of developmental/life-course violence, aggression, and delinquency trajectories: a state-of-the-art review. Journal of Criminal Justice, 40, 472-489. https://doi.org/10.1016/j.jcrimjus.2012.07.001.

Larsson, H., Viding, E., Rijsdijk, F. V., \& Plomin, R. (2008). Relationships between parental negativity and childhood antisocial behavior over time: A bidirectional effects model in a longitudinal genetically informative design. Journal of Abnormal Child Psychology, 36, 633-645. https://doi.org/10.1007/s00787013-0488-5.

Liska, A. E., \& Reed, M. D. (1985). Ties to conventional institutions and delinquency: estimating reciprocal effects. American Sociological Review, 547-560. https://doi.org/10.2307/2095438.

McElhaney, K. B., Porter, M. R., Thompson, L. W., \& Allen, J. P. (2008). Apples and oranges: divergent meanings of parents' and adolescents' perceptions of parental influence. Journal of Early adolescence, 28, 206-229. https://doi.org/10.1177/0272431607312768.

Meeus, W., van de Schoot, R., Keijsers, L., \& Branje, S. (2012). Identity statuses as developmental trajectories: a five-wave longitudinal study in early-to-middle and middle-to-late adolescents. Journal of Youth and Adolescence, 41, 1008-1021. https:// doi.org/10.1007/s10964-011-9730-y.

Moffitt, T. E. (1993). Adolescence-limited and life-course-persistent antisocial behavior: a developmental taxonomy. Psychological Review, 100, 674. https://doi.org/10.1037/0033-295x.100.4.674.

Moffitt, T. E Life course persistent versus adolescence-limited antisocial behavior. In D.Cicchetti \& D.Cohen (Eds) Developmental psychopathology (pp. 570-578). New York: Wiley.

Moffitt, T. E., Caspi, A., Dickson, N., Silva, P., \& Stanton, W. (1996). Childhood-onset versus adolescent-onset antisocial conduct problems in males: Natural history from ages 3 to 18 years. Development and Psychopathology, 8, 399-424. https://doi.org/10. 1017/s0954579400007161.

Moffitt, T. E., \& Silva, P. A. (1988). Self-reported delinquency: Results from an instrument for New Zealand. Australian and New Zealand Journal of Criminology, 21, 227-240. https://doi.org/10. 1177/000486588802100405.

Monahan, K. C., Steinberg, L., Cauffman, E., \& Mulvey, E. P. (2009). Trajectories of antisocial behavior and psychosocial maturity from adolescence to young adulthood. Developmental Psychology, 45, 1654-1668. https://doi.org/10.1037/a0015862.

Miller, I. W., Epstein, N. B., Bishop, D. S., \& Keitner, G. I. (1985). The McMaster family assessment device: reliability and validity. Journal of Marital and Family Therapy, 11, 345-356. https://doi. org/10.1111/j.1752-0606.1985.tb00028.x.

Muthén, B. O. (2003). Statistical and substantive checking in growth mixture modeling. Psychological Methods, 8, 369-377. https:// doi.org/10.1037/1082-989X.8.3.369.

Muthén, B., \& Muthén, L. K. (2000). Integrating person-centered and variable-centered analyses: Growth mixture modeling with latent trajectory classes. Alcoholism: Clinical and Experimental Research, 24, 882-891. https://doi.org/10.1097/00000374-200006000-00020.

Nagin, D. (2005). Group-based modeling of development. Cambridge: Harvard University Press.

Odgers, C. L., Moffitt, T. E., Broadbent, J. M., Dickson, N., Hancox, R. J., Harrington, H., \& Caspi, A. (2008). Female and male antisocial trajectories: from childhood origins to adult outcomes. Development and Psychopathology, 20, 673-716. https://doi.org/ 10.1017/s0954579408000333.

Oldehinkel, A. J., Rosmalen, J. G., Buitelaar, J. K., Hoek, H. W., Ormel, J., Raven, D., \& Hartman, C. A. (2015). Cohort Profile Update: The TRacking Adolescents' Individual Lives Survey (TRAILS). International Journal of Epidemiology, 44, 76-76n. https://doi.org/10.1093/ije/dyu225.

Pardini, D. A., Fite, P. J., \& Burke, J. D. (2008). Bidirectional associations between parenting practices and conduct problems in boys from childhood to adolescence: the moderating effect of age and African-American ethnicity. Journal of Abnormal Child Psychology, 36, 647-662. https://doi.org/10.1007/s10802-0079162-Z.

Patterson, G. R. (1982). Coercive family process. Eugene: Castalia Publishing Company.

Phares, V., Compas, B. E., \& Howell, D. C. (1989). Perspectives on child behavior problems: Comparisons of children's self-reports with parent and teacher reports. Psychological Assessment, 1, $68-71$.

Piquero, A. R. (2008). Taking stock of developmental trajectories of criminal activity over the life course. In A. Liberman (Ed.), The long view of crime: A synthesis of longitudinal research (pp. 23-78). New York, NY: Springer.

Reitz, E., Deković, M., Meijer, A. M., \& Engels, R. C. (2006). Longitudinal relations among parenting, best friends, and early adolescent problem behavior testing bidirectional effects. Journal of Early Adolescence, 26, 272-295. https://doi.org/10.1177/ 0272431606288591. 
Roisman, G. I., Monahan, K. C., Campbell, S. B., Steinberg, L., \& Cauffman, E. (2010). Is adolescence-onset antisocial behavior developmentally normative? Development and Psychopathology, 22, 295-311. https://doi.org/10.1017/s0954579410000076.

Sameroff, A. J. (2009). The transactional model of development: How children and contexts shape each other. Washington, DC: American Psychological Association.

Schaeffer, C. M., Petras, H., Ialongo, N., Masyn, K. E., Hubbard, S., Poduska, J., \& Kellam, S. (2006). A comparison of girls' and boys' aggressive-disruptive behavior trajectories across elementary school: prediction to young adult antisocial outcomes. Journal of Consulting and Clinical Psychology, 74, 500. https:// doi.org/10.1037/0022-006x.74.3.500.

Stewart, E. A., Simons, R. L., Conger, R. D., \& Scaramella, L. V. (2002). Beyond the interactional relationship between delinquency and parenting practices: The contribution of legal sanctions. Journal of Research in Crime and Delinquency, 39, 36-59. https://doi.org/10.1177/002242780203900102.
Thornberry, T. P., Lizotte, A. J., Krohn, M. D., Farnworth, M., \& Jang, S. J. (1991). Testing interactional theory: an examination of reciprocal causal relationships among family, school, and delinquency. Journal of Criminal Law and Criminology, 82, 3-35. https://doi.org/10.1177/0022427897034003002.

Van Buuren, S., \& Groothuis-Oudshoorn, K. (2011). Mice: Multivariate imputation by chained equations in R. Journal of Statistical Software, 45, 1-67. https://doi.org/10.18637/jss.v045.i03.

Van de Schoot, R., Sijbrandij, M., Winter, S. D., Depaoli, S., \& Vermunt, J. K. (2017). The GRoLTS-checklist: guidelines for reporting on latent trajectory studies. Structural Equation Modeling: A Multidisciplinary Journal, 24, 451-467. https://doi.org/ 10.1080/10705511.2016.1247646.

Walls, T. A., Barta, W. D., Stawski, R. S., Collyer, C., \& Hofer, S. M. (2011). Time-scale-dependent longitudinal designs. In B. Laursen, T. D. Little \& N. A. Card (Eds), Handbook of developmental research methods (pp. 46-64). New York, NY: Guilford Press. 